\title{
Analysis of Some Biogenic Amines by Micellar Liquid Chromatography
}

\author{
Irena Malinowska and Katarzyna E. Stępnik \\ Chair of Physical Chemistry, Department of Planar Chromatography, Faculty of Chemistry, Maria Curie Skłodowska University, \\ M. Curie-Skłodowska Sq. 3, 20-031 Lublin, Poland \\ Correspondence should be addressed to Irena Malinowska, irena.malinowska@poczta.umcs.lublin.pl
}

Received 10 February 2012; Revised 8 May 2012; Accepted 22 May 2012

Academic Editor: Burcu Dogan-Topal

Copyright (๑) 2012 I. Malinowska and K. E. Stępnik. This is an open access article distributed under the Creative Commons Attribution License, which permits unrestricted use, distribution, and reproduction in any medium, provided the original work is properly cited.

\begin{abstract}
Micellar liquid chromatography (MLC) with the use of high performance liquid chromatography (HPLC) was used to determine some physicochemical parameters of six biogenic amines: adrenaline, dopamine, octopamine, histamine, 2-phenylethylamine, and tyramine. In this paper, an influence of surfactant's concentration and $\mathrm{pH}$ of the micellar mobile phase on the retention of the tested substances was examined. To determine the influence of surfactant's concentration on the retention of the tested amines, buffered solutions (at pH 7.4) of ionic surfactant—sodium dodecyl sulfate SDS (at different concentrations) with acetonitrile as an organic modifier $(0.8 / 0.2 \mathrm{v} / \mathrm{v})$ were used as the micellar mobile phases. To determine the influence of $\mathrm{pH}$ of the micellar mobile phase on the retention, mobile phases contained buffered solutions (at different $\mathrm{pH}$ values) of sodium dodecyl sulfate SDS (at $0.1 \mathrm{M}$ ) with acetonitrile $(0.8 / 0.2 \mathrm{v} / \mathrm{v})$. The inverse of value of retention factor $(1 / k)$ versus concentration of micelles $\left(C_{M}\right)$ relationships were examined. Other physicochemical parameters of solutes such as an association constant analyte-micelle $\left(K_{\mathrm{ma}}\right)$-and partition coefficient of analyte between stationary phase and water (hydrophobicity descriptor) $\left(P_{\mathrm{sw}} \Phi\right)$ were determined by the use of Foley's equation.
\end{abstract}

\section{Introduction}

Micellar liquid chromatography (MLC) is a mode of conventional reversed-phase liquid chromatography which uses a surfactant solution (anionic, cationic, or nonionic) above the critical micellar concentration $(\mathrm{cmc})$ as a mobile phase $[1,2]$. The retention of a compound in MLC depends on the type of interaction (electrostatic and/or hydrophobic) with the micelles and with a surfactant-modified stationary phase [2-5]. There is an assumption that there exist three different partition equilibria between: micellar mobile phase and water, micellar mobile phase and stationary phase, and stationary phase and aqueous mobile phase [1]. There are a lot of equations which describe interactions between these equilibria.

From the beginning of MLC in 1980, the technique has evolved up to become a real alternative in some instances to classical RPLC with hydro-organic mixtures, owing to its peculiar features and unique advantages [6]. MLC is an effective technique for analysis of the organic compounds with biological activity [7-9]. Amongst many advantages of MLC the following can be specified as the most important $[1,10-12]$ :

(i) low price of a mobile phase,

(ii) little toxicity in comparison with classical mobile phases in RP-HPLC,

(iii) possibility of separation of ionic and nonionic substances in the same column packing and the same distributing cycle,

(iv) possibility of control of system's selectivity through the modification of simple parameters of mobile phase such as surfactant's concentration, $\mathrm{pH}$, or ionic strength,

(v) possibility of fast modification of concentration gradient. 
The biogenic amines are the group of compounds which are formed during many important intracellular metabolic processes [13]; these amines are the products of transformation of amino acids or their derivatives. In the living organism, the biogenic amines take physiological roles which are important for the correct course of many biological processes [14]. The biogenic amines are necessary for keeping an existence of cell. They are the part of coenzymes and might be hormones. In cells, among other things, amines have an effect on DNA replication and cell permeability and might control mammal's lactation. Some of these are carcinogenic.

In this paper, some biogenic amines (adrenaline, dopamine, octopamine, 2-phenylethylamine, tyramine, and histamine) were determined.

Biogenic amines are damaging to health because they are substrates in the carcinogenic compound synthesisnitrosoamines. The presence of histamine in food (i.e., in cheese or fish) can result in strong alimentary intoxication $[15,16]$.

Adrenaline is a hormone and neurotransmitter which takes a role of stress mechanism that is lightning reactions of living organism to stress. Adrenaline can increase heart rate, constrict blood vessels, dilate air passages, and participate in the fight-or-flight response of the sympathetic nervous system. Adrenaline also increases cerebral blood flow and hence oxygen delivery to the brain $[17,18]$.

Dopamine is called the hormone of happiness. Dopamine is available as an intravenous medication acting on the sympathetic nervous system, producing effects such as increased heart rate and blood pressure. It is involved in the regulation of a variety of functions, including locomotor activity, emotion and affect, and neuroendocrine secretion [19].

Histamine is a powerful biologically active substance, and therefore it can exert many responses within the body. Histamine exerts its effects by binding to receptors on cellular membranes which are found in the cardiovascular system and in various secretory glands [20].

Octopamine is an endogenous biogenic amine that is closely related to noradrenaline. It has effects on the adrenergic and dopaminergic systems. Octopamine has been reported to influence animal behavior, such as avoidance conditioning or motor activity $[21,22]$.

Many derivates of 2-phenylethylamine are psychoactive and psychedelic. This amine as a hormone and neurotransmitter takes a fundamental role in nervous system. Moreover, it is present in food, mainly in chocolate, and also in some species of mushrooms $[23,24]$.

Tyramine acts mainly indirectly by releasing noradrenaline from the sympathetic nervous system which causes an increase of the blood pressure by peripheral vascoconstriction and by increasing the cardiac output [15].

Due to biogenic amines are a large group of naturally occurring biologically active compounds, which are present in food products and can act as hormones and neurotransmitters, there are many different analytical techniques for their quantitative and qualitative determination. Amongst chromatographic techniques the most commonly used are RP-LC [25-28], MEKC [29, 30], and IEC [31-33]. MLC technique for the determination of biogenic amines is rather rarely applied.

Paleologos and coworkers successfully separated nine biogenic amines (cadaverine, tyramine, putrescine, agamatine, spermidine, tryptamine, phenylalanine, spermine, and histamine) in the form of benzoyl derivatives by the use of MLC with gradient elution. Investigated biogenic amines were quantitatively and qualitatively determined in fish products [34].

Bose and coworkers used MLC technique for the determination of dopamine and serotonine and their metabolites (homovalinic acid (HVA) and hydroxyindoleacetic acid (HIAA)) and tyramine in the serum samples [35]. Other biogenic amines (such as tyramine and tryptamine and their precursors: thyrosine and tryptophan) were determined in MLC systems in vine samples [36].

\section{Experimental}

2.1. Apparatus. Chromatographic data were obtained using Shimadzu Vp liquid chromatographic system equipped with an LC 10AT pump, an SPD 10A UV-VIS detector, an SCL 10A system controller, a CTO-10 AS chromatographic oven, and a Rheodyne injector valve with $20 \mu \mathrm{L}$ loop. This system utilizes a class-Vp computer program to control hardware, acquire and store data, and determine retention times.

A stainless-steel column $(125 \times 4 \mathrm{~mm}$, I.D. $)$ packed with $5 \mu \mathrm{m}$ RP-8 endcapped Purospher (Merck) was used in each experiment.

The flow rate was $1.0 \mathrm{~mL} \mathrm{~min}^{-1}$. All measurements were carried out at $20^{\circ} \mathrm{C}$. The test compounds were detected at $230 \mathrm{~nm}$.

2.2. Reagents and Materials. Stock standards of six biogenic amines (Table 1): adrenaline, dopamine, histamine, octopamine, 2-phenylethylamine, and tyramine were purchased from Sigma Aldrich (St. Louis, USA).

All stock solutions of the analytes were prepared with the concentration of about $0.1 \mathrm{mg} \mathrm{mL}^{-1}$ in methanol.

For the determination of the influence of surfactant's concentration on the retention, mobile-phases-buffered solutions at $\mathrm{pH} 7.4$ of sodium dodecyl sulfate (SDS) at the concentrations of $0.02 \mathrm{M}, 0.04 \mathrm{M}, 0.06 \mathrm{M}, 0.08 \mathrm{M}$, and $0.1 \mathrm{M}+$ acetonitrile as an organic modifier (for HPLC) at the concentration of $20 \% \mathrm{v} / \mathrm{v}$ were used. After measuring of SDS concentration, the organic modifier was added, so the real concentrations of SDS were correspondingly $0.016 \mathrm{M}$, $0.032 \mathrm{M}, 0.048 \mathrm{M}, 0.064 \mathrm{M}$, and $0.08 \mathrm{M}$.

The buffer was prepared with $\mathrm{Na}_{2} \mathrm{HPO}_{4}(0.02 \mathrm{M})$ and citric acid $(0.01 \mathrm{M})$ and was vacuum-filtered through $0.45 \mu \mathrm{m}$ membrane filter before use. $\mathrm{pH}$ value of this buffer was measured before the preparation of the mobile phases. Distilled water was obtained from Direct-Q UV apparatus (Millipore). Acetonitrile (for HPLC) at the concentration of $20 \% \mathrm{v} / \mathrm{v}$ was utilized as an organic modifier. Micellar mobile phases were degassed in the ultrasonic bath for about two minutes before use.

For the determination of the influence of $\mathrm{pH}$ of the micellar mobile phase on the retention, mobile-phases-buffered 
TABLE 1: Structures of tested substances.

\begin{tabular}{|c|c|c|}
\hline Number & Name & Structures of tested substances \\
\hline 1 & Adrenaline & $\mathrm{OH}$ \\
\hline 2 & Dopamine & $\mathrm{OH}$ \\
\hline 3 & Octopamine & $\mathrm{H}$ \\
\hline 4 & Histamine & $\mathrm{H}$ \\
\hline 5 & 2-phenylethylamine & \\
\hline 6 & Tyramine & $\mathrm{HO}$ \\
\hline
\end{tabular}

solutions at $\mathrm{pH} 3,4,5,6,7.4,8$, and 9 of sodium dodecyl sulfate (SDS) at the concentration of $0.1 \mathrm{M}$ were used. The buffer in the same way as presented above was prepared. Acetonitrile (for HPLC) at the concentration of $20 \% \mathrm{v} / \mathrm{v}$ was utilized as an organic modifier.

\section{Result and Discussion}

Besides that MLC is an acknowledged analytical technique, it has high significance in elementary research.

There are many agents in MLC which have an effect on retention such as $[5,37]$ :

(i) type of organic modifier,

(ii) concentration of organic modifier,

(iii) concentration of surfactant (concentration of micelles),

(iv) $\mathrm{pH}$ of mobile phase.

In this paper, an influence of surfactant's concentration and $\mathrm{pH}$ of the micellar mobile phase on the retention of tested substances were examined.

3.1. An Influence of Surfactant's Concentration on the Retention of Tested Amines. For this purpose, the retention of tested substances was defined in the following mobile phase: buffer ( $\mathrm{pH} 7.4)+$ acetonitrile + SDS (of variable concentration).

The buffer solution at $\mathrm{pH} 7.4$ was used for the reason that in biology and medicine, this value is often referred to as physiological (the $\mathrm{pH}$ of blood is usually slightly basic with a value of $\mathrm{pH}$ 7.365) [38] and tested substances are very closely connected with many processes in the living organism.

The research of variation of retention factor in relation to the concentration of surfactant can give much important information applying to interactions of tested substances with components of the micellar mobile phase.

The analysis of the relationship: inverse of value of retention factor $(1 / k)$ versus concentration of micelles $\left(C_{M}\right)$ can give information about the type of interaction between tested solutes and micelles [39] and can determine such physicochemical parameters of solutes as an association constant analyte-micelle $\left(K_{\mathrm{ma}}\right)$ - and can compare partition coefficient between micellar mobile phase and water $\left(P_{\mathrm{sw}} \Phi\right)$ $[12,40]$.

If substance does not work with micelle, the change of retention was not observed with the change of concentration of surfactant.

If substance acts with micelle, decrease of retention was observed with increase of surfactant's concentration (the socalled binding analyte) [39].

In case of the increase of retention, it was noticed that substance from micelle was eliminated with the increase of surfactant's concentration (the so-called antibinding analyte) [39].

Linear, ascending relationship between $1 / k$ value and concentration of micelles with high coefficient of determination $\left(R^{2}>0.96\right)$ was obtained for all investigated solutes (Figure 1). The character of relationships involves the fact that all tested biogenic amines act with micelles of the mobile phase (are so-called binding analytes).

3.2. Calculations of Chosen Physicochemical Parameters. Linear relationships $1 / k=f\left(C_{M}\right)$ can be presented in the following way $[12,40]$ (Foley's equation):

$$
\frac{1}{k}=\frac{K_{\mathrm{ma}} C_{M}}{P_{\mathrm{sw}} \Phi}+\frac{1}{P_{\mathrm{sw}} \Phi}
$$

where $C_{M}$ : concentration of micelles, $K_{\mathrm{ma}}$ : analyte-micelle association constant, $P_{\mathrm{sw}}$ : partition coefficient of analyte between stationary phase and water; hydrophobicity descriptor, and $\Phi$-volume ratio of stationary phase to volume of mobile phase.

The slope of a straight line from (1) is formulated as $K_{\mathrm{ma}} /\left(P_{\mathrm{sw}} \Phi\right)$ and free term in an expression as $1 / P_{\mathrm{sw}} \Phi$.

The slope of a straight line informs about substance's sensitivity to the change of concentration of surfactant, therefore shows the possibility of modification retention through the change of surfactant's concentration. Moreover, the slope of a straight line $1 / k=f\left(C_{M}\right)$ depends on the interaction of the substance with micelle $\left(K_{\mathrm{ma}}\right)$ and on partition coefficient between stationary phase and water $\left(P_{\mathrm{sw}}\right)$ (Table 2). 


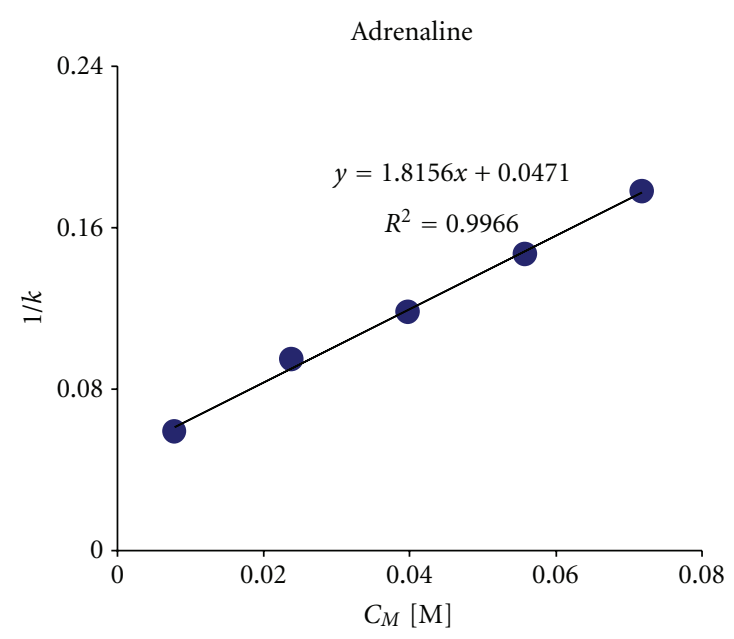

(a)

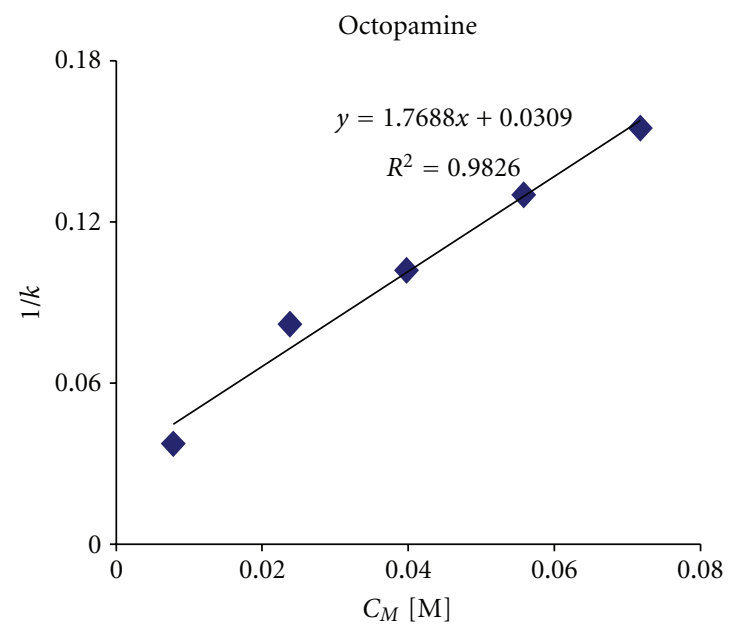

(c)

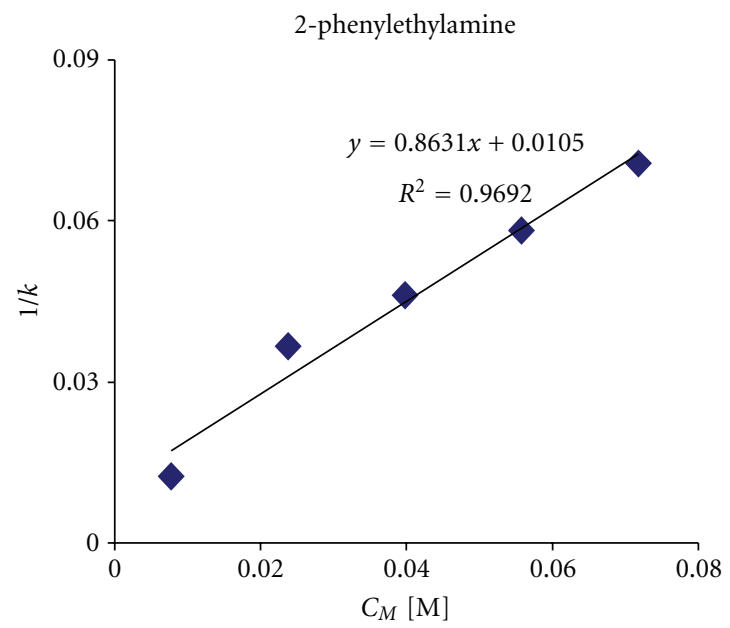

(e)

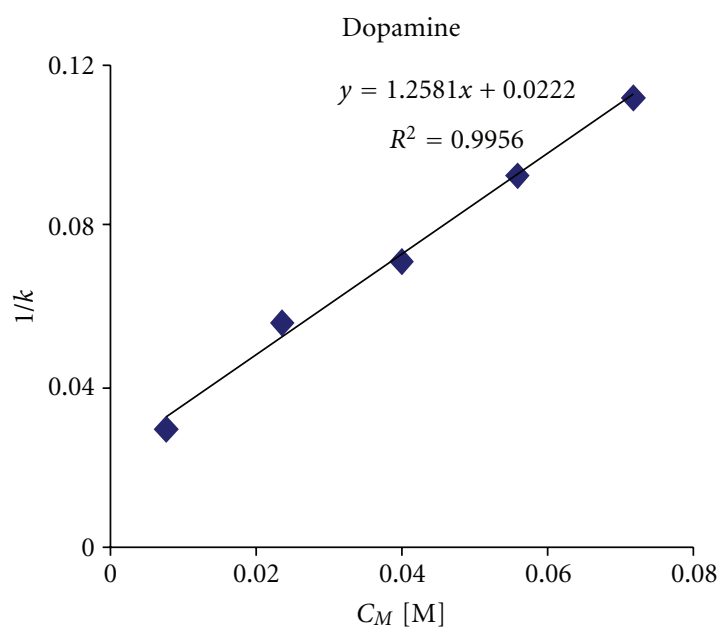

(b)

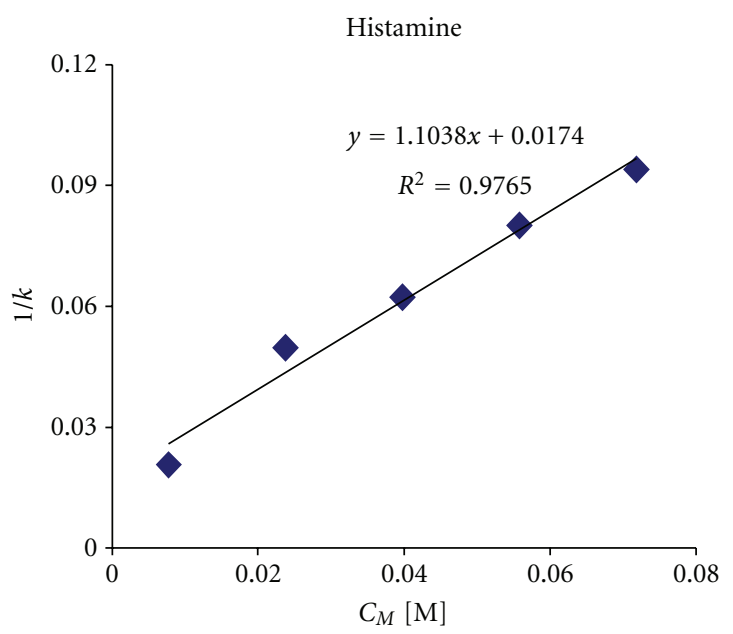

(d)

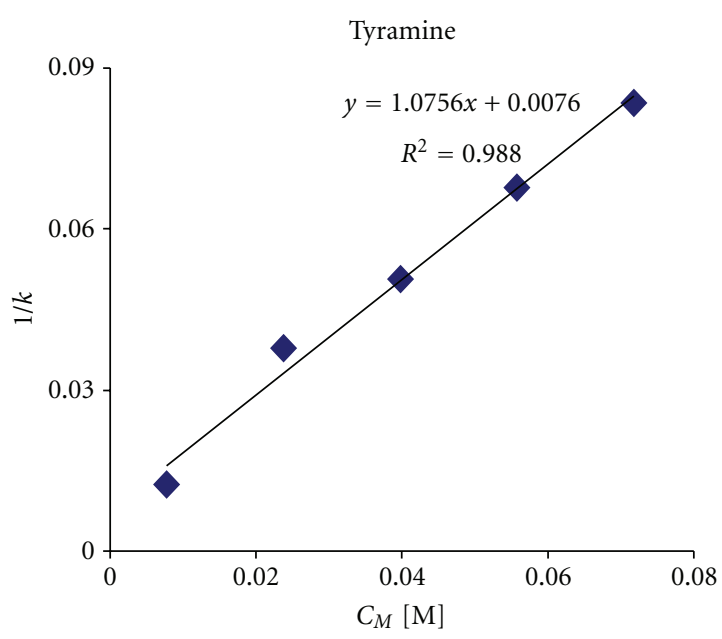

(f)

Figure 1: $1 / k$ versus $C_{M}$ relationships obtained for all tested biogenic amines. 
TABle 2: $K_{\mathrm{ma}} / P_{\mathrm{sw}} \Phi, K_{\mathrm{ma}}$ and $P_{\mathrm{sw}} \Phi$ values of tested biogenic amines according to (1).

\begin{tabular}{lcccc}
\hline Solute number & Name & $K_{\mathrm{ma}} / P_{\mathrm{sw}} \Phi$ & $K_{\mathrm{ma}}$ & $P_{\mathrm{sw}} \Phi$ \\
\hline 1 & adrenaline & 1.82 & 38.55 & 21.23 \\
2 & dopamine & 1.26 & 56.67 & 45.05 \\
3 & octopamine & 1.77 & 57.24 & 32.36 \\
4 & histamine & 1.10 & 63.44 & 37.47 \\
5 & 2-phenylethylamine & 0.86 & 82.20 & 95.24 \\
6 & tyramine & 1.08 & 141.53 & 131.58 \\
\hline
\end{tabular}

Obtained values of $K_{\mathrm{ma}}$ (Table 2) demonstrate that tyramine acts the most strongly and adrenaline the most weakly with SDS micelle. Almost all of calculated values are larger than 1 , which means that analyte-micelle interaction has higher influence than analyte-modified stationary phase on the retention of biogenic amines. Only 2-phenylethylamine demonstrates other type of interaction which suggests higher impact of analyte-modified stationary phase interaction on the retention of this amine.

Moreover, $1 / b=P_{\mathrm{sw}} \Phi$ value can inform also about hydrophobicity relations of tested substances.

Because of large difficulty to determine $\Phi$ value, it is given as $P_{\mathrm{sw}} \Phi$ value, because at the given chromatographic system $\Phi$ value is constant. $P_{\mathrm{sw}} \Phi$ value informs about relative hydrophobicity of tested substances. When analyte acts more strongly with micelle, it acts more weakly with water.

On the basis of the $P_{\mathrm{sw}} \Phi$ values, it was demonstrated that tyramine is the most hydrophobic solute and adrenaline the least. The obtained $K_{\text {ma }}$ values show that the increase of solutes hydrophobicity increases $K_{\text {ma }}$ values.

In the micellar systems, the retention of the solutes depends on their hydrophobic properties.

Therefore, $\log k$ versus $\log P_{\mathrm{sw}} \Phi$ relationships were determined for all chromatographic systems (Figure 2).

Very good $\log k$ versus $\log P_{\text {sw }} \Phi$ linear relationships $\left(R^{2}>\right.$ 0.98 ) suggest that $P_{\mathrm{sw}} \Phi$ parameter should be considered as good hydrophobicity descriptor for tested solutes despite using different concentrations of surfactant in the micellar mobile phases.

3.3. An Influence of $p H$ of the Micellar Mobile Phase on the Retention of Tested Substances. Due to possible existence of many different forms of biogenic amines [41], the $\mathrm{pH}$ of the micellar mobile phase is a very important agent which can influence the retention of tested substances [42].

For this purpose, the retention of tested substances was defined in the following mobile phases: acetonitrile $(4: 1$ $\mathrm{v} / \mathrm{v})+$ SDS at the concentration of $0.1 \mathrm{M}+$ citric buffer at different $\mathrm{pH}(3,4,5,6,7.4,8$, and 9). Due to stability of chromatographic column, the range of $\mathrm{pH}$ was as present above.

In Figure 3 there is a comparison of obtained relationships ( $k$ versus $\mathrm{pH}$ ) with the literature data [41] related to the range of $\mathrm{pH}$ in which particular forms of tested substances exist for chosen biogenic amines.

As we can observe, depending on the $\mathrm{pH}$ value, the forms of tested substances are replaced. These changes influence the retention value.

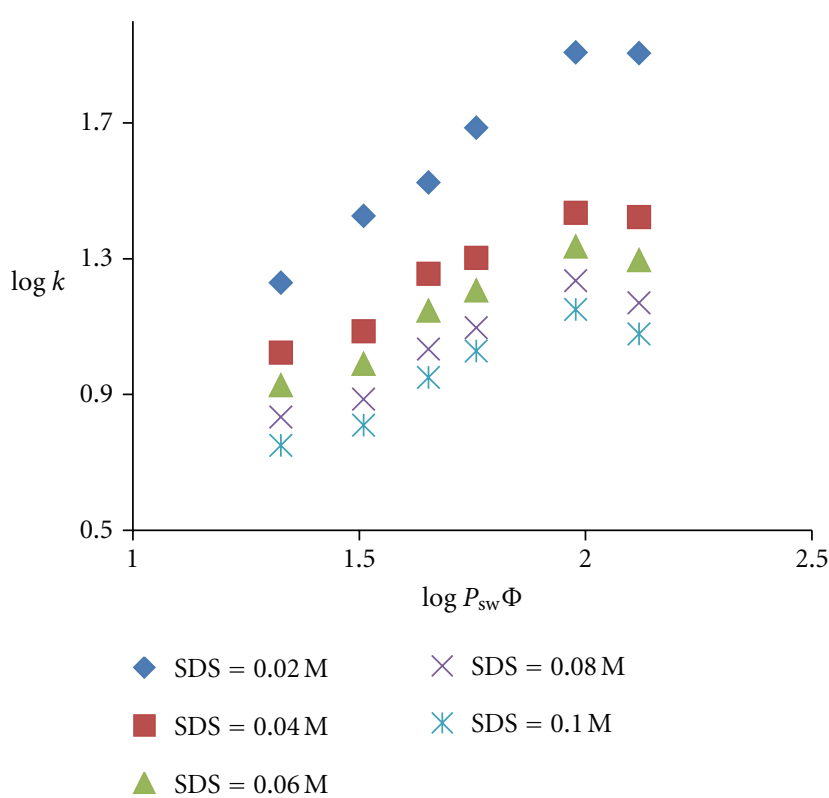

FIGURE 2: $\log k$ versus $\log P_{\text {sw }} \Phi$ relationships for all types of micellar mobile phases.

TABLE 3: pKa values of tested biogenic amines in the examined $\mathrm{pH}$ range.

\begin{tabular}{lc}
\hline Substance name & pKa value \\
\hline adrenaline & 8.91 \\
dopamine & 9.27 \\
histamine & 9.58 \\
octopamine & 8.98 \\
2-phenylethylamine & 9.79 \\
tyramine & 9.66 \\
\hline
\end{tabular}

MLC technique can be used as an instrument to verify or even determine such physicochemical parameters as $\mathrm{pKa}$ in examined $\mathrm{pH}$ range [41] (Table 3). In this case, the limitation of $\mathrm{pH}$ range, caused by the stability of chromatographic column, makes the calculation of $\mathrm{pKa}$ impossible.

3.4. The Analytical Aspect of MLC. Except for defined physicochemical parameters through the data obtained from the retention, the MLC performs a role as the analytical method. In this paper, it was also examined what was a separation possibility of analyzed biogenic amines in the tested systems. Because surfactant's concentration (concentration of micelles) effects on retention of tested substances, in the mobile phases at the different concentration of SDS (but at the same amount of other components), the longest time of retention was observed at the lowest concentration of surfactant.

For the micellar mobile phase: $0.02 \mathrm{M}$ SDS + acetonitrile $(4: 1 \mathrm{v} / \mathrm{v})$ at $\mathrm{pH} 7.4$, the best separation was achieved for five tested amines out of six that were tested (except 2phenylethylamine which retention time is almost the same as the retention time of tyramine). However, time of analysis 


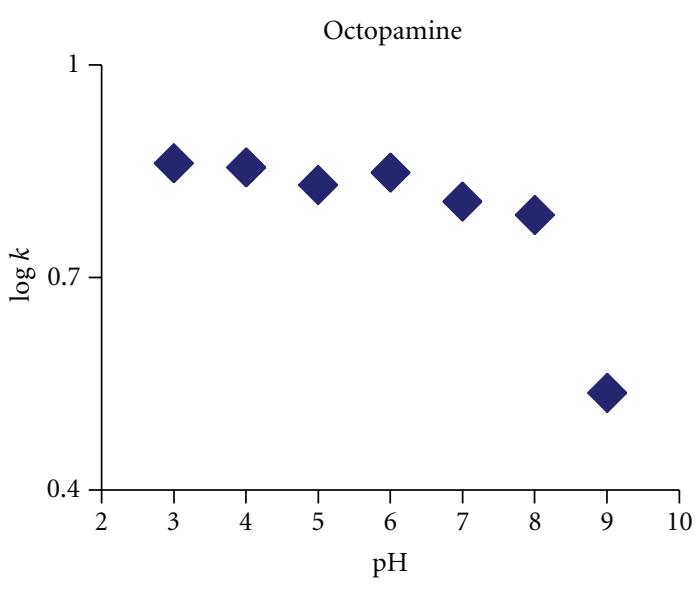

(a)

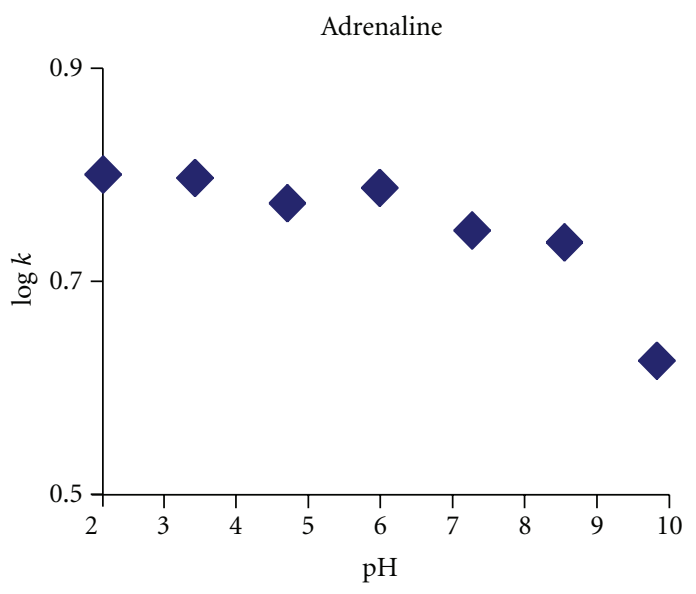

(c)

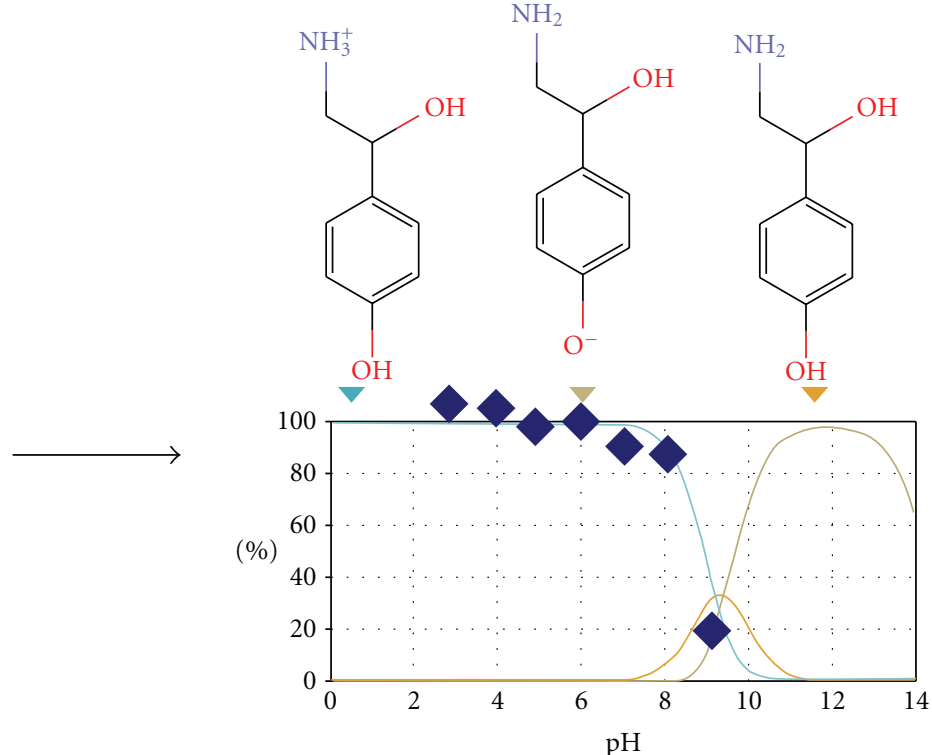

(b)

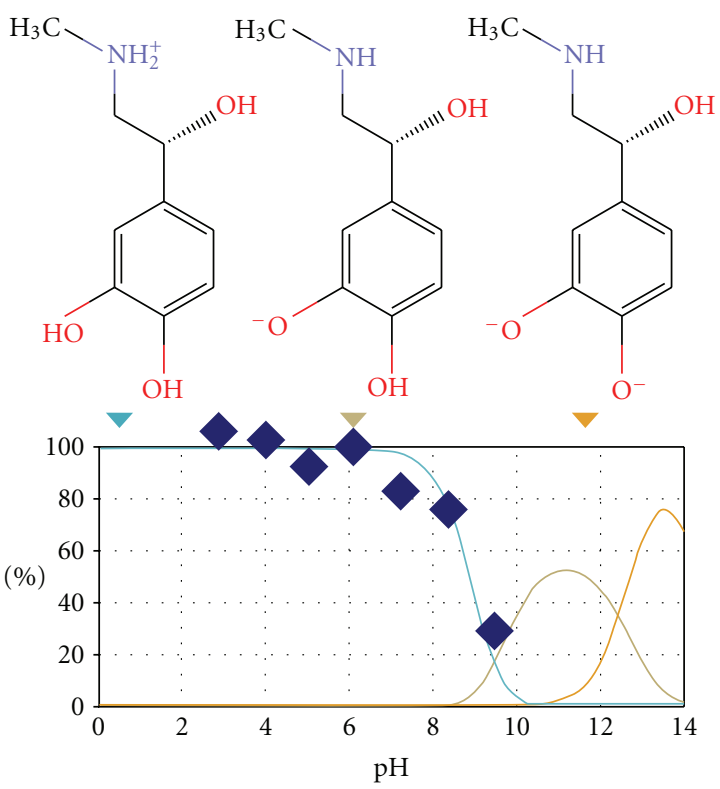

(d)

FIGURE 3: The comparison of obtained relationships $\log k$ versus $\mathrm{pH}$ of the micellar mobile phase with the pKa of tested amines.

using this mobile phase is about 50 minutes and peaks of the substances at the longest retention time (histamine and tyramine), are diffused. It is comprehensible, because it is a result of a diffusion. On the other hand, the separation of adrenaline (peak 1), octopamine (peak 2), and dopamine (peak 3) is satisfactory $\left(R_{\mathrm{s} 12}=5.04, R_{\mathrm{s} 23}=3,30\right)$. Time of analysis for these three compounds is about 25 minutes. Therefore, for the determination of these amines mobile phase with $0.02 \mathrm{M}$ SDS will be the most appropriate (Figure 4).

The retention time decreases with the surfactant's concentration. The increase of surfactant's concentration to $0.04 \mathrm{M}$ induces the worse separation of adrenaline and octopamine $\left(R_{\mathrm{s} 12}=0.42\right)$, but separation of octopamine and dopamine is acceptable $\left(R_{\mathrm{s} 23}=1.29\right)$ (to the zero line). The improvement of the shape of peaks 4 and 5 (histamine and tyramine) is noticeable in comparison with the mobile phase presented above, peaks 3 and 4 overlap.

The successive increase of SDS concentration to $0.06 \mathrm{M}$ does not have an effect on the systems' resolution, but the time of analysis is observably shorter.

The next increase of SDS concentration results in no separation of adrenaline and octopamine, but dopamine, histamine, and tyramine to the zero line are separated and for such mixture, mobile phase with $0.08 \mathrm{M}$ SDS would be better than mobile phase with $0.06 \mathrm{M}$ SDS. In this mobile phase, 


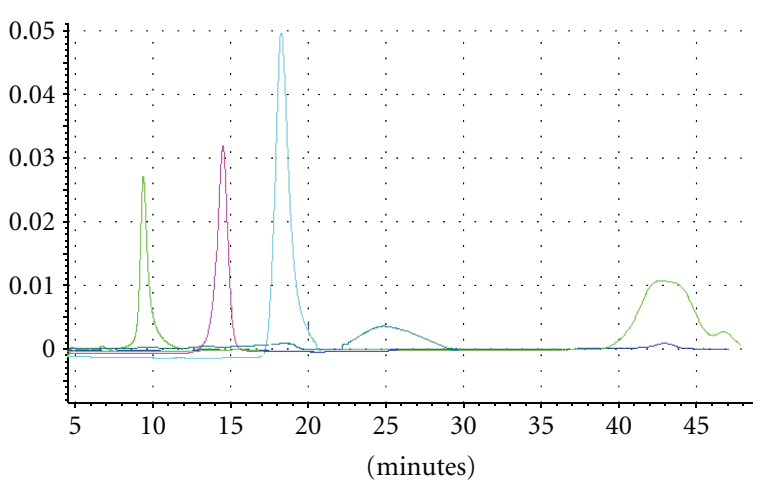

FIGURE 4: The chromatogram of the separation of tested amines: $0.02 \mathrm{M}$ SDS (pH 7.4) + acetonitrile (20\% v/v).

the separation and the identification of 4 out of 5 tested amines is practically possible.

At the mobile phase with the highest concentration of SDS $(0.1 \mathrm{M})$ (retention times are the shortest), the overlapping of all peaks is observed, therefore this phase is not suitable for the analytical purpose.

\section{Conclusions}

For all tested biogenic amines, the decrease of retention (increase of $1 / k$ ) with the increase of surfactant's concentration in the micellar mobile phase was observed. Very good $1 / k$ value versus $C_{M}$ linear relationships with high coefficient of determination confirm the above dependence. An impact of the surfactant's concentration in the micellar mobile phase on retention of tested amines was proved. The slope of the change of retention line $1 / k=f\left(C_{M}\right)$ depends mainly on hydrophobicity of analytes. Linear, ascending relationship between $1 / k$ value and concentration of micelles with high coefficient of determination was obtained for all investigated solutes (Figure 1). The character of relationships involves the fact that all tested biogenic amines act with micelles of the mobile phase (are binding analytes).

To determine this attribute $P_{\mathrm{sw}}$ and $K_{\mathrm{ma}}$ values were calculated. On the basis of the $P_{\mathrm{sw}} \Phi$ values it was demonstrated that tyramine is the most hydrophobic solute and adrenaline the least. The obtained $K_{\text {ma }}$ values show that the increase of solutes hydrophobicity, involves the increase of $K_{\mathrm{ma}}$ values. Moreover, between $K_{\mathrm{ma}}$ values significant differences for different tested amines were visible. The rise of $P_{\mathrm{sw}} \Phi$ value responds to the increase of analytes retention. The above results prove that the concentration of surfactant in the micellar mobile phase is a very important agent that influences the retention of organic compounds. Therefore, the optimization of chromatographic systems in MLC through the choice of concentration of surfactant in the micellar mobile phase is necessary.

The investigated micellar chromatographic systems can be used for the separation and the determination of tested biogenic amines.

\section{References}

[1] D. W. Armstrong and F. Nome, "Partitioning behavior of solutes eluted with micellar mobile phases in liquid chromatography," Analytical Chemistry, vol. 53, no. 11, pp. 1662$1666,1981$.

[2] A. Berthod and M. C. García-Álvarez, Coque, Micellar Liquid Chromatography, vol. 83, Marcel Dekker, New York, NY, USA, 2000, Edited by J. Cazes.

[3] J. M. Sanchis Mallols, R. M. Villanueva Camañas, S. Sagrado, and M. J. Medina-Hernández, "Quantitative retentionstructure and Retention-activity relationship studies of ionic and non-ionic catecholamines by micellar liquid chromatography," Chromatographia, vol. 46, no. 11-12, pp. 605-612, 1997.

[4] M. J. Medina-Hernández and M. C. García-Álvarez-Coque, "Solute-mobile phase and solute-stationary phase interactions in micellar liquid chromatography. A review," Analyst, vol. 117, pp. 831-837, 1992.

[5] A. Berthod, I. Girard, and C. Gonnet, "Micellar liquid chromatography. Retention study of solutes of various polarities," Analytical Chemistry, vol. 58, no. 7, pp. 1359-1362, 1986.

[6] M. J. Ruiz-Ángel, S. Carda-Broch, J. R. Torres-Lapasió, and M. C. García-Álvarez-Coque, "Retention mechanisms in micellar liquid chromatography," Journal of Chromatography A, vol. 1216, no. 10, pp. 1798-1814, 2009.

[7] G. Maiti, A. P. Walvekar, and T. S. Krishnamoorthy, "Separation and determination of inorganic anions by highperformance liquid chromatography using a micellar mobile phase," Analyst, vol. 114, no. 6, pp. 731-733, 1989.

[8] F. P. Tomasella, P. Zuting, and L. J. Chin Love, "Determination of sun-screen agents in cosmetic products by micellar liquid chromatography," Journal of Chromatography, vol. 587, no. 2, pp. 325-328, 1991.

[9] M. G. Khaleda and E. D. Breyer, "Quantitation of hydrophobicity with micellar liquid chromatography," Analytical Chemistry, vol. 61, no. 9, pp. 1040-1047, 1989.

[10] P. Yarmchuck, R. Weinberger, R. F. Hirsch, and L. J. ClineLove, "Selectivity in liquid chromatography with micellar mobile phases," Analytical Chemistry, vol. 54, pp. 2233-2238, 1982.

[11] R. A. Barford and B. Sliwinski, "Micellar chromatography of proteins," Analytical Chemistry, vol. 56, no. 9, pp. 1554-1556, 1984.

[12] J. P. Foley, "Critical compilation of solute-micelle binding constants and related parameters from micellar liquid chromatographic measurements," Analytica Chimica Acta, vol. 23, pp. 237-247, 1990.

[13] S. Oguri, "Electromigration methods for amino acids, biogenic amines and aromatic amines," Journal of Chromatography B, vol. 747, no. 1-2, pp. 1-19, 2000.

[14] G. Suzzi and F. Gardini, "Biogenic amines in dry fermented sausages: a review," International Journal of Food Microbiology, vol. 88, no. 1, pp. 41-54, 2003.

[15] H. Zhai, X. Yang, L. Li et al., "Biogenic amines in commercial fish and fish products sold in southern China," Food Control, vol. 25, no. 1, pp. 303-308, 2012.

[16] H. M. L. J. Joosten, “The biogenic amine contents of Dutch cheese and their toxicological significance," Netherlands Milk and Dairy Journal, vol. 42, no. 1, pp. 25-42, 1988.

[17] R. E. Jackson, K. Joyce, S. F. Danosi, B. C. White, D. Vigor, and T. J. Hoehner, "Blood flow in the cerebral cortex during cardiac resuscitation in dogs," Annals of Emergency Medicine, vol. 13, no. 9, pp. 657-659, 1984. 
[18] J. Johansson, R. Gedeborg, S. Basu, and S. Rubertsson, "Increased cortical cerebral blood flow by continuous infusion of adrenaline (epinephrine) during experimental cardiopulmonary resuscitation," Resuscitation, vol. 57, no. 3, pp. 299 $307,2003$.

[19] M. Jaber, S. W. Robinson, C. Missale, and M. G. Caron, "Dopamine receptors and brain function," Neuropharmacology, vol. 35, no. 11, pp. 1503-1519, 1996.

[20] A. R. Shalaby, "Significance of biogenic amines to food safety and human health," Food Research International, vol. 29, no. 7, pp. 675-690, 1996.

[21] J. Delacour, J. F. Coulon, J. C. David, and C. Guenaire, "Brain octopamine and strain differences in avoidance behavior," Brain Research, vol. 288, no. 1-2, pp. 169-176, 1983.

[22] T. Bungo, T. Higaki, H. Ueda, and M. Furuse, "Intracerebroventricular administration of octopamine stimulates food intake of chicks through $\alpha 2$-adorenoceptor," Physiology and Behavior, vol. 76, no. 4-5, pp. 575-578, 2002.

[23] B. Pfundstein, A. R. Tricker, E. Theobald, B. Spiegelhalder, and R. Preussmann, "Mean daily intake of primary and secondary amines from foods and beverages in West Germany in 19891990," Food and Chemical Toxicology, vol. 29, no. 11, pp. 733739, 1991.

[24] M. H. Silla Santos, "Biogenic amines: their importance in foods," International Journal of Food Microbiology, vol. 29, no. 2-3, pp. 213-231, 1996.

[25] S. Jia, Y. P. Kang, J. H. Park, J. Lee, and S. W. Kwon, "Simultaneous determination of 23 amino acids and 7 biogenic amines in fermented food samples by liquid chromatography/quadrupole time-of-flight mass spectrometry," Journal of Chromatography A, vol. 1218, no. 51, pp. 9174-9182, 2011.

[26] H. M. Mao, B. G. Chen, X. M. Qian, and Z. M. Liu, "Simultaneous determination of twelve biogenic amines in serum by high performance liquid chromatography," Microchemical Journal, vol. 91, no. 2, pp. 176-180, 2009.

[27] G. Sagratini, S. Vittor, M. Fernandez-Franzon, G. Font, and F. De Berardinis, "Simultaneous determination of eight underivatised biogenic amines in fish by solid phase extraction and liquid chromatography-tandem mass spectrometry," Food Chemistry, vol. 132, no. 1, pp. 537-543, 2012.

[28] T. Tang, T. Shi, K. Qian, P. Li, J. Li, and Y. Cao, "Determination of biogenic amines in beer with pre-column derivatization by high performance liquid chromatography," Journal of Chromatography B, vol. 877, no. 5-6, pp. 507-512, 2009.

[29] I. Rodriguez, H. K. Lee, and S. F. Y. Li, "Separation of biogenic amines by micellar electrokinetic chromatography," Journal of Chromatography A, vol. 745, no. 1-2, pp. 255-262, 1996.

[30] G. Nouadje, N. Siméon, F. Dedieu, M. Nertz, P. Puig, and F. Couderc, "Determination of twenty eight biogenic amines and amino acids during wine aging by micellar electrokinetic chromatography and laser-induced fluorescence detection," Journal of Chromatography A, vol. 765, no. 2, pp. 337-343, 1997.

[31] M. Triki, F. Jimenez-Colmenero, A. M. Herrero, and C. RuizCapillas, "Optimisation of a chromatographic procedure for determining biogenic amine concentrations in meat and meat products employing a cation-exchange column with a postcolumn system," Food Chemistry, vol. 130, no. 4, pp. 10661073, 2012.

[32] B. M. De Borba and J. S. Rohrer, "Determination of biogenic amines in alcoholic beverages by ion chromatography with suppressed conductivity detection and integrated pulsed amperometric detection," Journal of Chromatography A, vol. 1155, no. 1, pp. 22-30, 2007.
[33] G. Saccani, E. Tanzi, P. Pastore, S. Cavalli, and M. Rey, "Determination of biogenic amines in fresh and processed meat by suppressed ion chromatography-mass spectrometry using a cation-exchange column," Journal of Chromatography A, vol. 1082, no. 1, pp. 43-50, 2005.

[34] E. K. Paleologos, S. D. Chytiri, I. N. Savvaidis, and M. G. Kontominas, "Determination of biogenic amines as their benzoyl derivatives after cloud point extraction with micellar liquid chromatographic separation," Journal of Chromatography A, vol. 1010, no. 2, pp. 217-224, 2003.

[35] D. Bose, A. Durgbanshi, M. E. Capella-Peiró, M. Gil-Agustí, J. Esteve-Romero, and S. Carda-Broch, "Micellar liquid chromatography determination of some biogenic amines with electrochemical detection," Journal of Pharmaceutical and Biomedical Analysis, vol. 36, no. 2, pp. 357-363, 2004.

[36] M. Gil-Agustí, S. Carda-Broch, L. Monferrer-Pons, and J. Esteve-Romero, "Simultaneous determination of tyramine and tryptamine and their precursor amino acids by micellar liquid chromatography and pulsed amperometric detection in wines," Journal of Chromatography A, vol. 1156, no. 1-2, pp. 288-295, 2007.

[37] A. Berthod, M. F. Borgerding, and W. L. Hinze, "Investigation of the causes of reduced efficiency in micellar liquid chromatography," Journal of Chromatography, vol. 556, no. 1-2, pp. 263-275, 1991.

[38] W. F. Boron and E. L. Boulpaep, Medical Physiology: A Cellular and Molecular Approach, Saunders Elsevier, Philadelphia, Pa, USA, 2nd edition, 2009.

[39] D. W. Armstrong and G. Y. Stine, "Selectivity in pseudophase liquid chromatography," Analytical Chemistry, vol. 55, no. 14, pp. 2317-2320, 1983.

[40] A. Szymański, Badania retencyjne i oznaczanie wybranych sufloamidów w środkach spożywczych metodą micelarnej chromatografii cieczowej, Wydawnictwo Naukowe Uniwersytetu Adama Mickiewicza w Poznaniu, Poznań, 2006.

[41] http://www.chemicalize.org/.

[42] A. H. Rodgers, J. K. Strasters, and M. G. Khaledi, "Simultaneous optimization of $\mathrm{pH}$ and micelle concentration in micellar liquid chromatography," Journal of Chromatography, vol. 636, no. 2, pp. 203-212, 1993. 


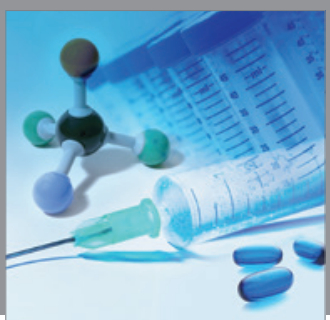

International Journal of

Medicinal Chemistry

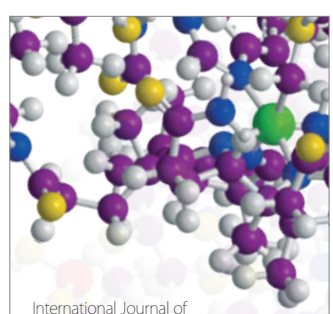

Carbohydrate Chemistry

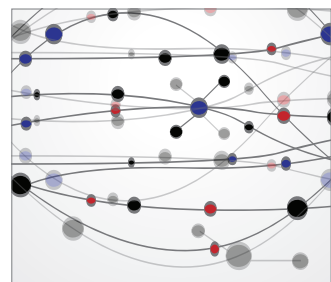

The Scientific World Journal
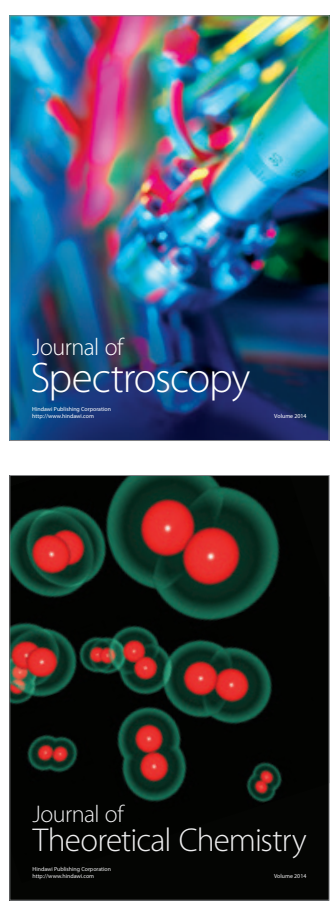
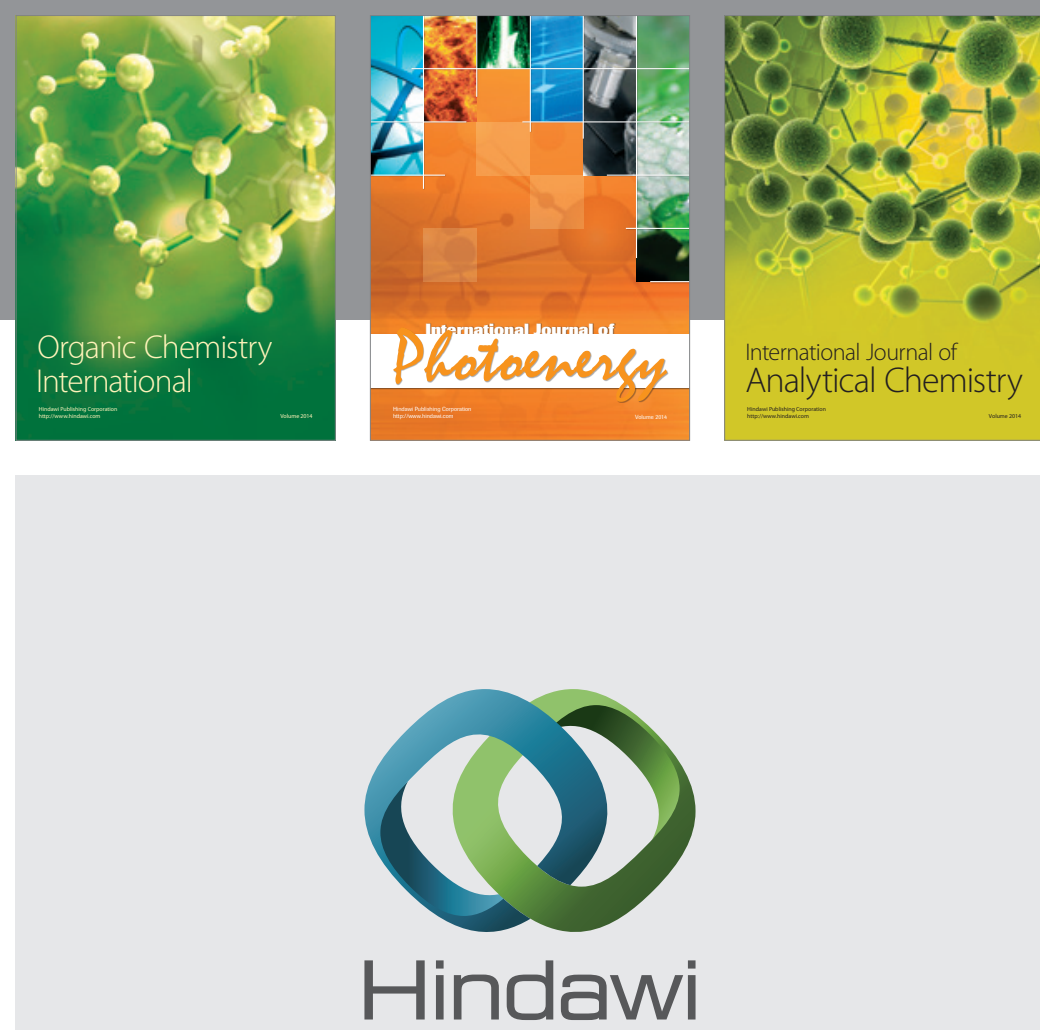

Submit your manuscripts at

http://www.hindawi.com
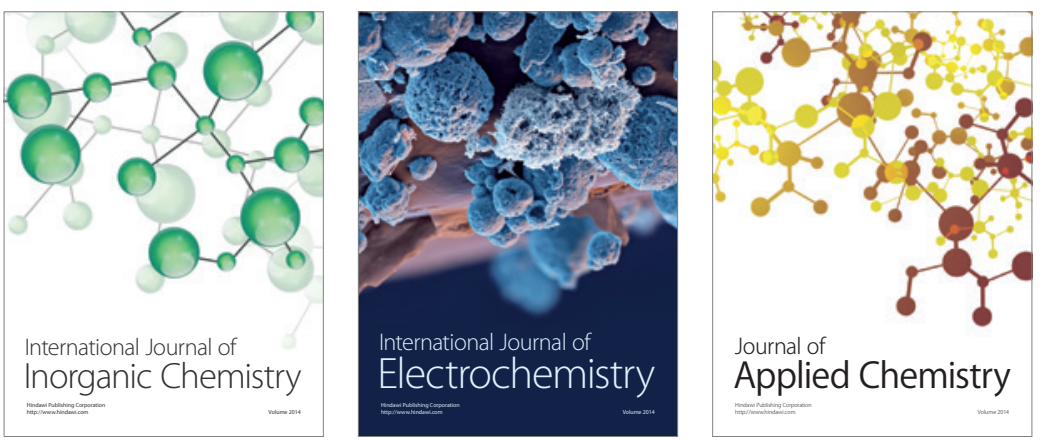

Journal of

Applied Chemistry
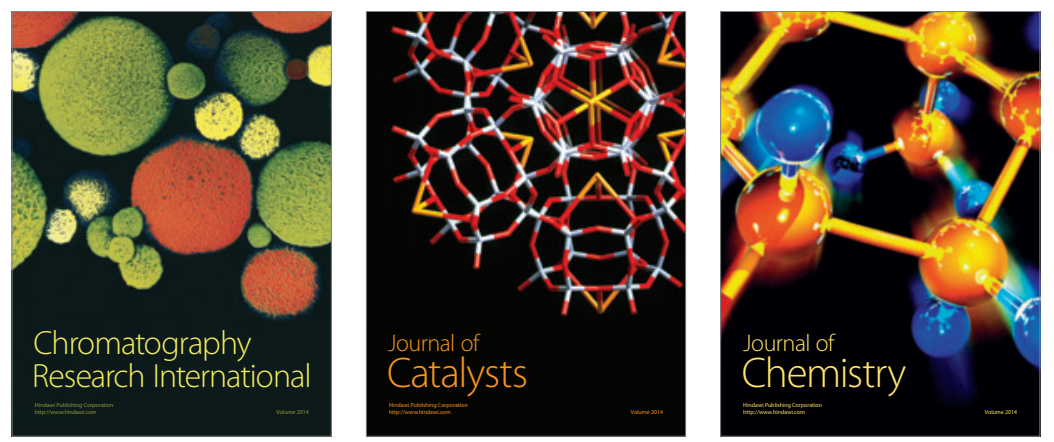
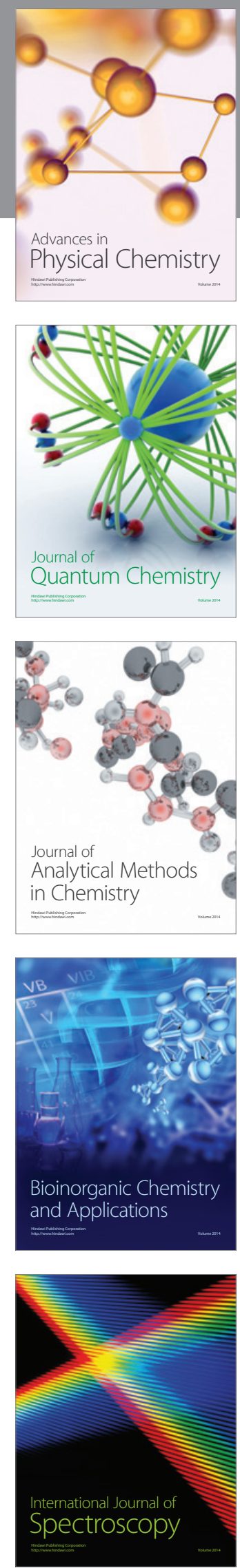